\title{
Co-seismic signatures in magnetometer, geophone, and infrasound data during the Meinong Earthquake
}

\author{
Jann-Yenq Liu ${ }^{1,2, *}$, Chieh-Hung Chen ${ }^{3}$, Tsung-Yu Wu ${ }^{1}$, Hsiao-Ching Chen ${ }^{1}$, Katsumi Hattori ${ }^{4}$, \\ I-Ching Yang ${ }^{2}$, Tom Bleier ${ }^{5}$, Karl Kappler ${ }^{5}$, Yaqin Xia ${ }^{6}$, Weisheng Chen ${ }^{6}$, and Zhengyan Liu ${ }^{7}$ \\ ${ }^{1}$ Institute of Space Science, National Central University, Taoyuan City, Taiwan \\ ${ }^{2}$ Department of Applied Science, National Taitung University, Taitung, Taiwan \\ ${ }^{3}$ Department of Earth and Environmental Sciences, National Chung Cheng University, Chiayi County, Taiwan \\ ${ }^{4}$ Graduate School of Science, Chiba University, Chiba, Japan \\ ${ }^{5}$ QuakeFinder, Palo Alto, CA, USA \\ ${ }^{6}$ Institute of Earthquake Prediction, Beijing University of Technology, Beijing, China \\ ${ }^{7}$ College of Mechanical Engineering and Applied Electronics Technology, Beijing University of Technology, Beijing, China
}

\section{Article history:}

Received 15 November 2016

Revised 2 March 2017

Accepted 5 March 2017

Keywords:

Co-seismic signature, Magnetometer, Geophone, Infrasound, QuakeFinder

Citation:

Liu, J.-Y., C.-H. Chen, T.-Y. Wu, H.-C. Chen, K. Hattori, I.-C. Yang, T. Bleier, K. Kappler, Y. Xia, W. Chen, and Z. Liu, 2017: Co-seismic signatures in magnetometer, geophone, and infrasound data during the Meinong Earthquake. Terr Atmos. Ocean. Sci., 28, 683-692, doi: 10.3319/TAO.2017.03.05.01

\begin{abstract}
This paper utilizes 10 stations of co-located seismometer, QuakeFinder/infrasound to observe co-seismic signatures triggered by the 6 February 2016 M 6.6 Meinong Earthquake. Each QuakeFinder system consists of a 3-axes induction magnetometer, an air conductivity sensor, a geophone, and temperature/relative humidity sensors. There are no obvious charges in the positive/negative ions, the temperature, and the humidity, while the magnetometer, the geophone, and infrasound data detect clear co-seismic signatures, similar to seismic waves recorded by seismometers. The magnetometers register high-frequency pulsations, like seismic waves, and superimpose with low-frequency variations, which could be caused by the magnetometer shaking/tilting and/or the underground water level change, respectively, upon the arrival of seismic waves. The spectrum centering around $2.0 \mathrm{~Hz}$ of the co-seismic geophone fluctuations is similar to that of the seismic waves. However, the energy of co-seismic geophone fluctuations (also magnetometer pulsations) yields an exponential decay to the distance of a station to the epicenter, while the energy of the seismic waves is inversely proportional to the square of the distance. This suggests that the mechanisms for detecting seismic waves of the QuakeFinder system and seismometers are different. In general, the geophone and magnetometer/infrasound system are useful to record high- and low-frequency seismic waves, respectively.
\end{abstract}

\section{INTRODUCTION}

Ground motions, due to earthquakes creating mechanical disturbances, trigger acoustic and/or gravity waves, termed seismo-traveling atmospheric disturbances (STADs), in the neutral atmosphere near the Earth's surface. Sometimes STADs could further travel into the ionosphere and interact with the ionized gas resulting in seismo-traveling ionospheric disturbances (STIDs) [see papers listed in Davies (1990)]. Traditionally, seismometers (also geophones) record seismic waves monitoring the Earth's surface motion (Shearer 1999), and infrasound systems measure atmospheric pressure changes induced by the Earth's surface mo-

\footnotetext{
* Corresponding author

E-mail: tigerjyliu@gmail.com
}

tion and/or seismic waves, mainly Rayleigh waves, on the ground (Mutschlecner and Whitaker 2005; Liu et al. 2006, 2010, 2016a). Meanwhile, scientists report magnetic pulsations triggered by seismic waves (Iyemori et al. 1996, 2005; Honkura et al. 2002; Abdul Azeez et al. 2009; Widarto et al. 2009; Hao et al. 2013; Gao et al. 2014; Yen et al. 2015; Liu et al. 2016a). However, in previous co-seismic geomagnetic variations observed in time scale of seconds were rare, because the amplitude is rather small. To detect such effects separating from the effect of magnetometer sensor oscillation, observations with high-time resolution (e.g., $1 \mathrm{~Hz}$ ) are necessary (Iyemori et al. 1996). Meanwhile, Liu et al. (1993) show that the amplitude of differential quantities is proportional to its oscillation angular frequency. Thus, an 
induction magnetometer has a better performance than a total field or a fluxgate one in detecting high-frequency/small pulsations. Note that a total field or a fluxgate magnetometer is suitable to observe long-period magnetic variations (such as magnetic storm).

To conduct the iSTEP (integrate Search for Taiwan Earthquake Precursor) project for integrate study and test earthquake precursors (Liu et al. 2016b, c), networks of 5 infrasound systems with a sampling rate of $10 \mathrm{~Hz}$ and 15 QuakeFinder systems with a sampling rate of $50 \mathrm{~Hz}$ have been setup and operated in Taiwan since 2013. The infrasound system registers atmospheric VLF (very low frequency, the period range $0.5-200 \mathrm{sec}$ ) sounds induced by the low frequency oscillation of the Earth's surface. On the other hand, each QuakeFinder system consists of a 3-axes induction magnetometer measuring magnetic pulsations, an air conductivity sensor probing positive/negative ion concentrations, a geophone detecting mechanical disturbances, and temperature and relative humidity sensors monitoring the system surroundings. Note that the QuakeFinder induction magnetometer has of the time resolution of $50 \mathrm{~Hz}$, and therefore it is very sensitive and suitable for detecting coseismic magnetic signatures.

At 03:57 local time (19:57 UTC) on 6 February 2016, an earthquake with a moment magnitude of 6.6 struck in the Meinong District of Kaohsiung in Taiwan. The earthquake $\left(22.92^{\circ} \mathrm{N}, 120.54^{\circ} \mathrm{E}\right)$ struck at a depth of around $14.6 \mathrm{~km}$. This comparatively shallow depth caused more intense reverberations on the surface, and resulted in widespread damage and 117 deaths. The earthquake is the deadliest earthquake in Taiwan since the 921 earthquake in 1999. In this paper, seismograms with a sampling rate of $200 \mathrm{~Hz}$ of the free field strong earthquake observation network published by Center Weather Bureau (http://gdms.cwb.gov.tw/ index.php) are used as a reference. Concurrent/co-located measurements of the seismometers and QuakeFinder systems together with infrasound systems are employed to observe seismic waves and disturbances in the neutral atmosphere near the Earth's surface of the Meinong Earthquake.

\section{EXPERIMENT SETUP AND OBSERVATION}

Since 3 out of 5 infrasound systems and 5 out of 15 QuakeFinder systems were not in full operation, mea- surements of 10 stations of co-located seismometers and QuakeFinders together with 2 infrasound systems are examined. The infrasound system has a sampling rate of $10 \mathrm{sps}$ (sample pre second) and a sensitivity of $0.01 \mathrm{~Pa}$ with the frequency range $0.5-200 \mathrm{sec}$ and a dynamic range of 80 $\mathrm{dB}$ (Xia et al. 2011). The sampling rate of the QuakeFinder is 50 sps. The magnetometer has the sensitivity at $1 \mathrm{~Hz}$ : $0.1 \mathrm{~V} \mathrm{nT}^{-1}$, and the noise level: $0.1 \mathrm{pT}$ per root $\mathrm{Hz}$ at $1 \mathrm{~Hz}$ and $0.02 \mathrm{pT}$ per root $\mathrm{Hz}$ at $10 \mathrm{~Hz}$. The geophone has the natural frequency $4.5 \pm 0.5 \mathrm{~Hz}\left(\max\right.$ tilt angle $\left.25^{\circ}\right)$ and the sensitivity of $27.0 \mathrm{~V} \mathrm{~m}^{-1} \mathrm{~s}^{-1} \pm 10 \%$. The air conductivity sensor yields the range/resolution: 1 million ions $\mathrm{cc}^{-1} \mathrm{~s}^{-1}$. range and 500 ions $\mathrm{cc}^{-1} \mathrm{~s}^{-1}$ resolution, and the accuracy: $+/-25 \%$ of reading. Table 1 lists the sampling rate and sensitivity (or range) of the QuakeFinder magnetometer and infrasound systems. Figure 1 displays locations of the Meinong Earthquake and the 10-stations of co-located seismometer and QuakeFinder/ infrasound system (for detail also see, Table 2).

A careful examination shows no obvious earthquake related signatures in the air conductivity, temperature and relative humidity. Therefore, we focus on measurements of the geophone and the magnetometer. Figure 2 reveals the 10 -station data that the magnetometer probes magnetic pulsations in $\mathrm{nT} \mathrm{s}^{-1}$ in the northward $\left(\dot{\mathrm{B}}_{\mathrm{N}}\right)$, eastward $\left(\dot{\mathrm{B}}_{\mathrm{E}}\right)$, and $\mathrm{Z}$ ( $\dot{\mathrm{B}}_{\mathrm{Z}}$, upward) directions, the geophone in the northward direction measures the ground velocity in $\mathrm{cm} \mathrm{s}^{-1}$, and the seismometer records the acceleration in $\mathrm{cm} \mathrm{s}^{-2}$ of the Earth's surface motion in northward $\left(\mathrm{a}_{\mathrm{N}}\right)$, eastward $\left(\mathrm{a}_{\mathrm{E}}\right)$, and upward $\left(\mathrm{a}_{\mathrm{z}}\right)$, as well as the infrasound system registers the near Earth's atmospheric pressure $(\mathrm{P})$ oscillations in $\mathrm{Pa}$, respectively, during the earthquake. It is clear that co-seismic signatures in the magnetic pulsations superpose up some longperiod variations. There are very strong interferences/noises in $\dot{\mathrm{B}}_{\mathrm{N}}$ and $\dot{\mathrm{B}}_{\mathrm{Z}}$ at Station $\mathrm{A}$; in $\dot{\mathrm{B}}_{\mathrm{N}}$ at Station $\mathrm{G}$; and in $\dot{\mathrm{B}}_{\mathrm{N}}$, $\dot{\mathrm{B}}_{\mathrm{E}}$, and $\dot{\mathrm{B}}_{\mathrm{Z}}$ at Station J. No obvious co-seismic signatures in $\dot{\mathrm{B}}_{\mathrm{E}}$ at Station F. Note that the pulsations at Station D are very different from those at the rest station. The co-seismic magnetic pulsations at each station last $150-300 \mathrm{sec}$, and those at Station D are even upto $1200 \mathrm{sec}$. The seismic waves generally yield similar patterns of wave packets in all the stations, except in Station $\mathrm{D}, \mathrm{a}_{\mathrm{N}}$ and $\mathrm{a}_{\mathrm{E}}$ being very different from $a_{z}$. Packets of the co-seismic geophone fluctuations are similar to those of seismometers, especially the two in the horizontal component, $\mathrm{a}_{\mathrm{N}}$ and $\mathrm{a}_{\mathrm{E}}$. Again, the pattern of

Table 1. Sampling Rate and Sensitivity of QuakeFinder and Infrasound System.

\begin{tabular}{ccc}
\hline Sensor & Sampling rate & Sensitivity (range) \\
\hline Magnetometer & $50 \mathrm{~Hz}$ & $0.1 \mathrm{~V} \mathrm{nT}^{-1}$ \\
\hline Geophone & $50 \mathrm{~Hz}$ & Natural frequency $4.5 \pm 0.5 \mathrm{~Hz}\left(\mathrm{Max}\right.$ tilt angle $25^{\circ}$ ) and the sensitivity of $27.0 \mathrm{~V} \mathrm{~m} \mathrm{~m}^{-1} \pm 10 \%$ \\
\hline Air conductivity sensor & $50 \mathrm{~Hz}$ & 1 million ions cc $\mathrm{sec}^{-1} \mathrm{range}^{-1}$ and 500 ions cc $^{-1} \mathrm{sec}^{-1}$ resolution, and the accuracy: $+/-25 \%$ of reading \\
\hline Infrasound & $10 \mathrm{~Hz}$ & $0.01 \mathrm{~Pa}^{2}$ with the frequency range $0.5-200$ sec and a dynamic range of $80 \mathrm{~dB}$ \\
\hline
\end{tabular}




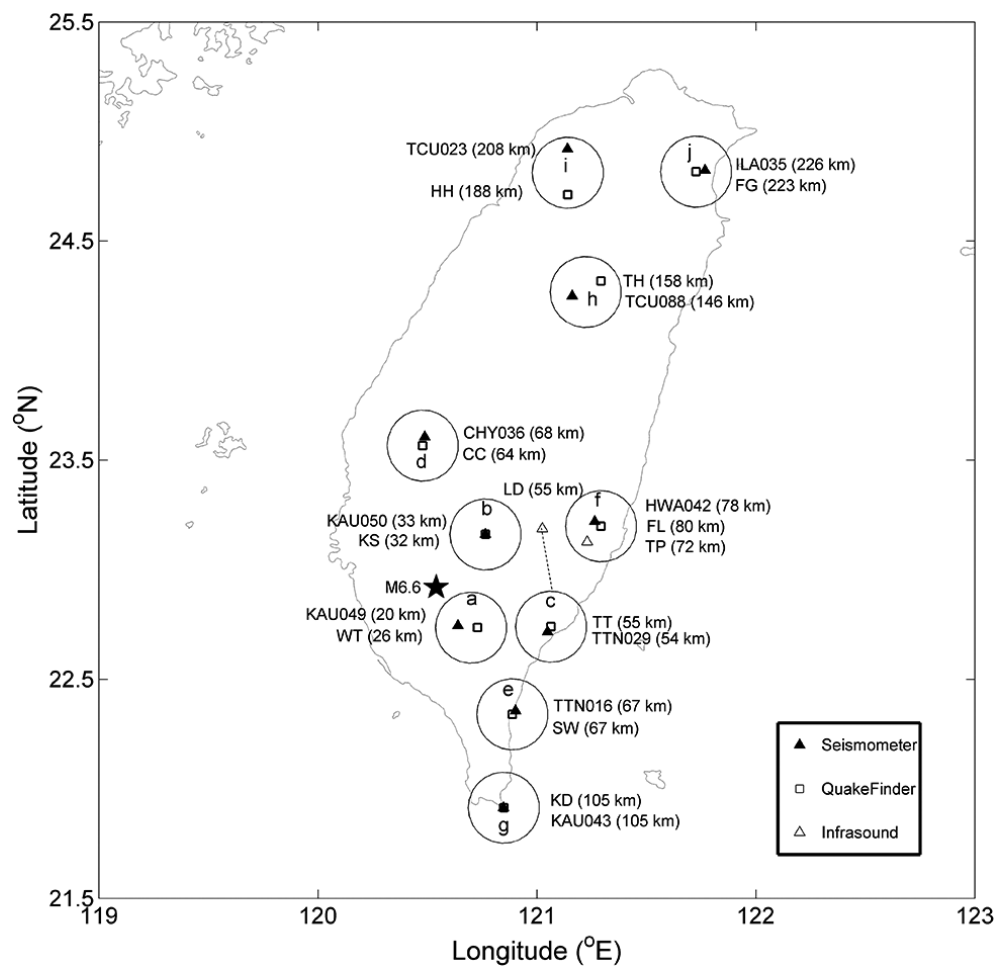

Fig. 1. Locations of the Meinong Earthquake and 10 stations of co-located QuakeFinder sites, seismometers, and infrasound systems. Note that one infrasound system is very near Station F but the other is far from Station C. Note that the station is denoted in lowercase character in figures, but in uppercase in the text.

Table 2. Station Location, Distance to the Epicenter and the Arrival Time.

\begin{tabular}{|c|c|c|c|c|c|c|c|c|c|}
\hline Station & Latitude $\left({ }^{\circ} \mathbf{N}\right)$ & Longitude $\left({ }^{\circ} \mathbf{E}\right)$ & Distance to epicenter (km) & \multicolumn{3}{|c|}{ Ticking time (s) } & \multicolumn{3}{|c|}{ Packet time (s) } \\
\hline Wu Tai (WT) & 22.7352 & 120.7292 & 26.45 & \multicolumn{3}{|c|}{6} & \multicolumn{3}{|c|}{10.4} \\
\hline KAU049 & 22.7443 & 120.6402 & 22.48 & 6 & 6 & 6 & 11.2 & 11 & 10.7 \\
\hline Kaosiung City (KS) & 23.1607 & 120.7653 & 32.97 & \multicolumn{3}{|c|}{8} & \multicolumn{3}{|c|}{14.2} \\
\hline KAU050 & 23.1607 & 120.7658 & 35.58 & 8 & 8 & 8 & 15.5 & 17.1 & 14.8 \\
\hline Tatung (TT) & 22.7398 & 121.0649 & 55.50 & \multicolumn{3}{|c|}{11} & \multicolumn{3}{|c|}{20.1} \\
\hline TTN029 & 22.7165 & 121.0490 & 54.92 & 12 & 12 & 12 & 21.5 & 21.6 & 20.6 \\
\hline Chung Cheng (CC) & 23.5663 & 120.4788 & 64.92 & \multicolumn{3}{|c|}{26} & \multicolumn{3}{|c|}{25.7} \\
\hline CHY036 & 23.6061 & 120.4884 & 76.89 & 36 & 34 & 35 & 48.2 & 45.82 & 38.1 \\
\hline Shang Wu (SW) & 22.3399 & 120.8879 & 67.64 & \multicolumn{3}{|c|}{13} & \multicolumn{3}{|c|}{27.6} \\
\hline TTN016 & 22.3558 & 120.9035 & 72.40 & 14 & 14 & 14 & 34.2 & 29.9 & 33.6 \\
\hline Fuli 2 (FL) & 23.1982 & 121.2933 & 80.30 & \multicolumn{3}{|c|}{17} & \multicolumn{3}{|c|}{30.8} \\
\hline HWA042 & 23.2198 & 121.2645 & 80.85 & 16 & 16 & 15 & 28 & 28.4 & 18 \\
\hline Ken Ding (KD) & 21.9134 & 120.8488 & 105.29 & \multicolumn{3}{|c|}{23} & \multicolumn{3}{|c|}{42.7} \\
\hline KAU043 & 21.9133 & 120.8488 & 116.74 & 22 & 22 & 19 & 45.7 & 42 & 43.7 \\
\hline Huan Shan $(\mathrm{TH})$ & 24.3174 & 121.2930 & 158.74 & \multicolumn{3}{|c|}{30} & \multicolumn{3}{|c|}{56.3} \\
\hline TCU088 & 24.2490 & 121.1615 & 160.81 & 28 & 28 & 27 & 55 & 47.1 & 46.8 \\
\hline Hengshan $2(\mathrm{HH})$ & 24.7118 & 121.1409 & 188.99 & \multicolumn{3}{|c|}{36} & \multicolumn{3}{|c|}{58} \\
\hline TCU023 & 24.7200 & 121.1399 & 209.25 & 36 & 38 & 37 & 69.9 & 65.5 & 66.64 \\
\hline Fo Guang (FG) & 24.8165 & 121.7270 & 223.74 & \multicolumn{3}{|c|}{40} & \multicolumn{3}{|c|}{71.8} \\
\hline ILA035 & 24.8224 & 121.7684 & 245.51 & 40 & 40 & 41 & 82.6 & 71.7 & 68.4 \\
\hline Li Dao (LD) & 23.1867 & 121.0249 & 55.35 & \multicolumn{3}{|c|}{12} & \multicolumn{3}{|c|}{28.8} \\
\hline Tаро (TP) & 23.1262 & 121.2305 & 72.06 & \multicolumn{3}{|c|}{16} & \multicolumn{3}{|c|}{30.9} \\
\hline
\end{tabular}


(a) WT / KAU049

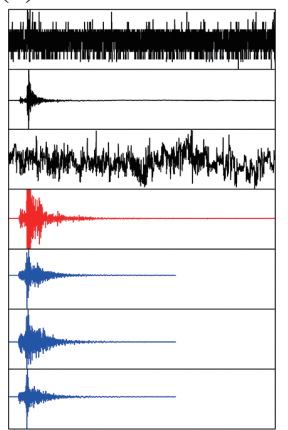

(b) KS / KAU050

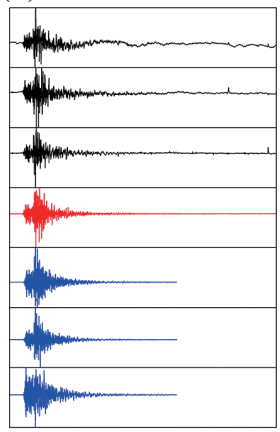

(c) TT / TTN029/ LD

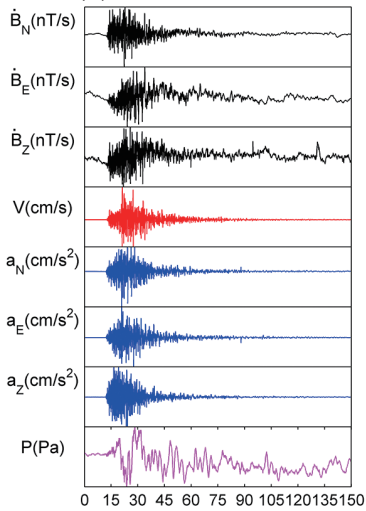

(d) $\mathrm{CC} / \mathrm{CHY} 036$

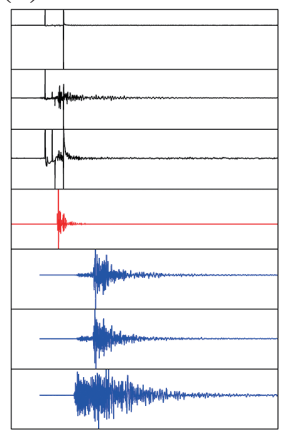

(e) SW / TTN016

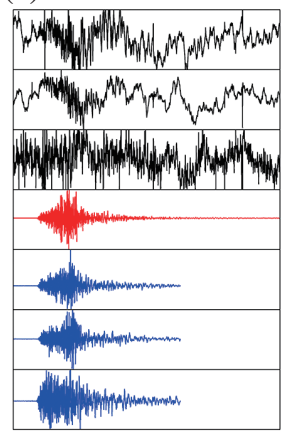

(f) FL / HWA042/ TP

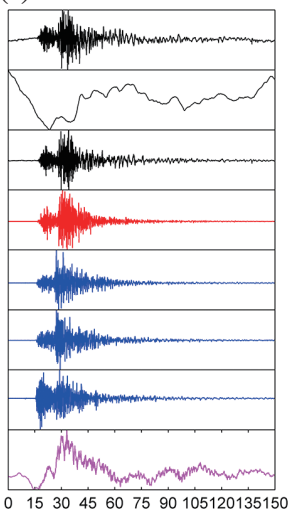

(g) KD / KAU043

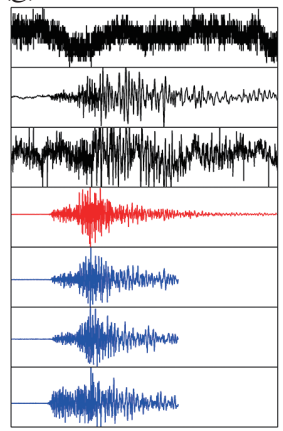

(h) $\mathrm{TH} / \mathrm{TCU} 088$

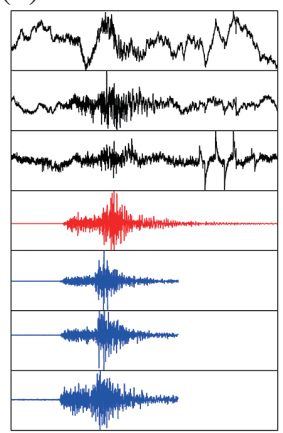

(i) $\mathrm{HH} / \mathrm{TCU} 023$

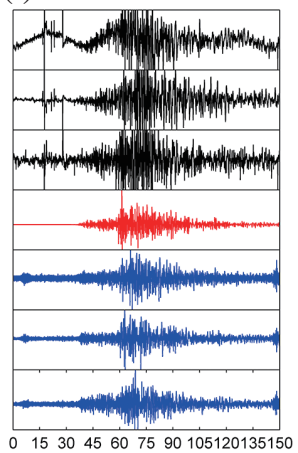

(j) FG / ILA035

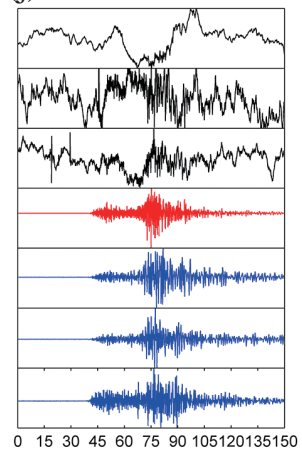

$0 \longdiv { 1 5 3 0 4 5 6 0 7 5 9 0 1 0 5 1 2 0 1 3 5 1 5 0 }$

Time after earthquake (sec)

Fig. 2. Raw data recorded by the magnetometers, the geophones, and seismometers, infrasound systems. For top to down, magnetic pulsations in $\mathrm{nT}$ in the $\mathrm{N}$ (northward, $\dot{\mathrm{B}}_{\mathrm{N}}$ ), E (eastward, $\dot{\mathrm{B}}_{\mathrm{E}}$ ), and Z (upward, $\dot{\mathrm{B}}_{\mathrm{Z}}$ ) directions, the geophone oscillations in $\mathrm{cm} / \mathrm{s}$, and the seismograms in $\mathrm{cm} \mathrm{s} \mathrm{s}^{-2}$ in northward $\left(\mathrm{a}_{\mathrm{N}}\right)$, eastward $\left(\mathrm{a}_{\mathrm{E}}\right)$, and upward $\left(\mathrm{a}_{\mathrm{Z}}\right)$, and infrasonic waves in Pa, respectively. The station locations of (a) to (j) are given in Fig. 1. (Color online only)

co-seismic geophone fluctuations at Station D is very much dissimilar to that of the rest stations. Figure 3 displays the relative power spectrum of the co-seismic magnetic pulsations, geophone fluctuations, seismic waves, and infrasound oscillations. It can be seen that the power density of the spectra in the magnetic pulsations and/or infrasound oscillations are inversely proportional to the frequency, while the co-seismic geophone fluctuations and the seismic waves yield the spectrum peaks around $2.0 \mathrm{~Hz}$. Thus, seismometers and geophones perform as high-frequency detectors, while magnetometers and infrasound systems act as lowfrequency ones for studying seismic waves.
We further examine the packet energy, which is the sum of the square of wave amplitudes over the packet, of the seismic waves and/or the co-seismic signatures of the Meinong earthquake. Figure 4 depicts the packet energy at each station versus the distance of a station to the epicenter. Results show that the packet energy of the seismic waves is inversely proportional to the square of distance, which suggests the seismic waves being from a point source (i.e., the epicenter or hypocenter). On the other hand, the packet energies recorded by the co-seismic geophone fluctuations and the co-seismic magnetic pulsations have the best fitting by exponential curves. This discrepancy might result from 


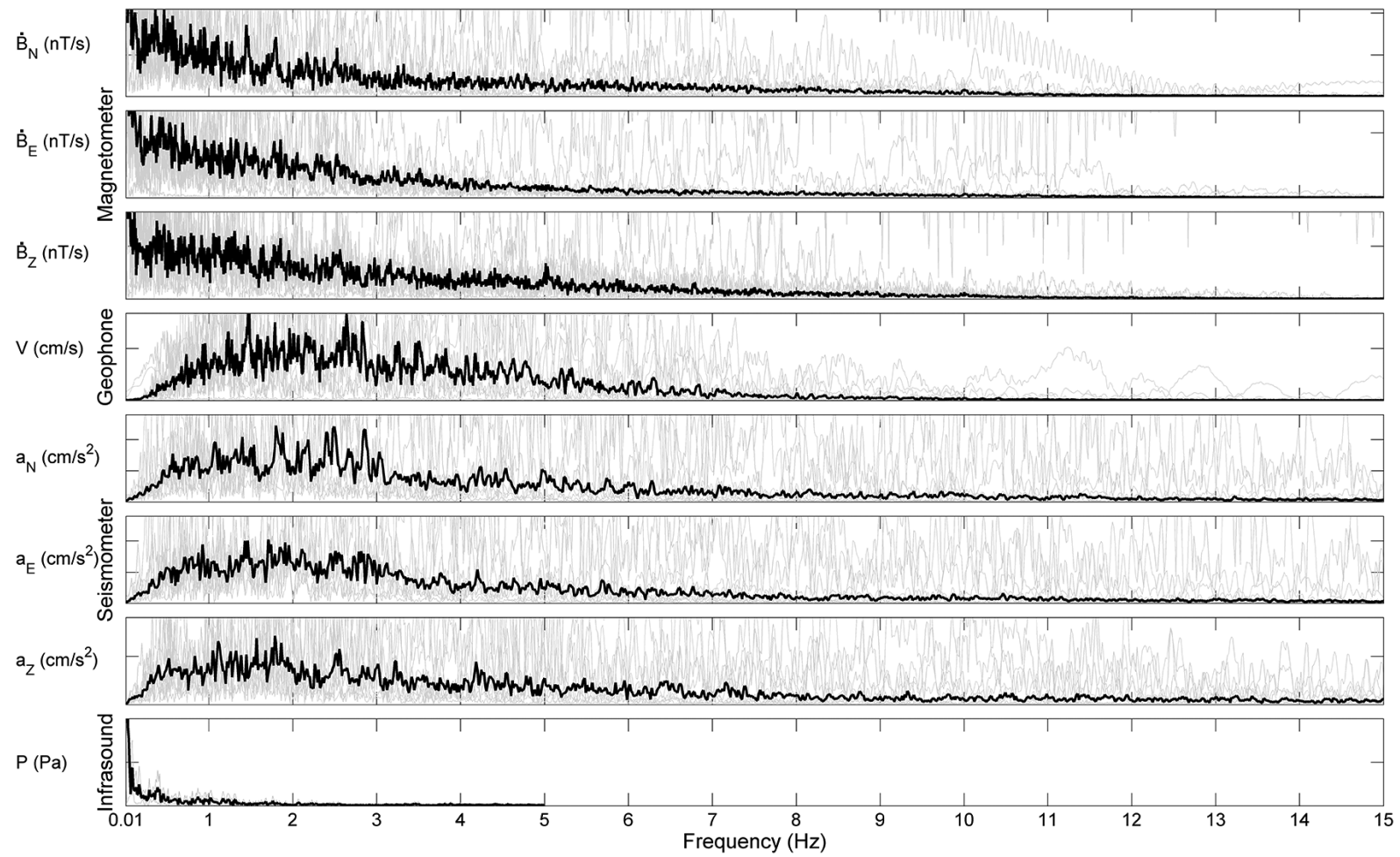

Fig. 3. Power spectrum of the raw data of the magnetometers, the geophones, and seismometers, infrasound systems. The gray curves are the individual spectrum, while the heavy curves are their associated median ones.
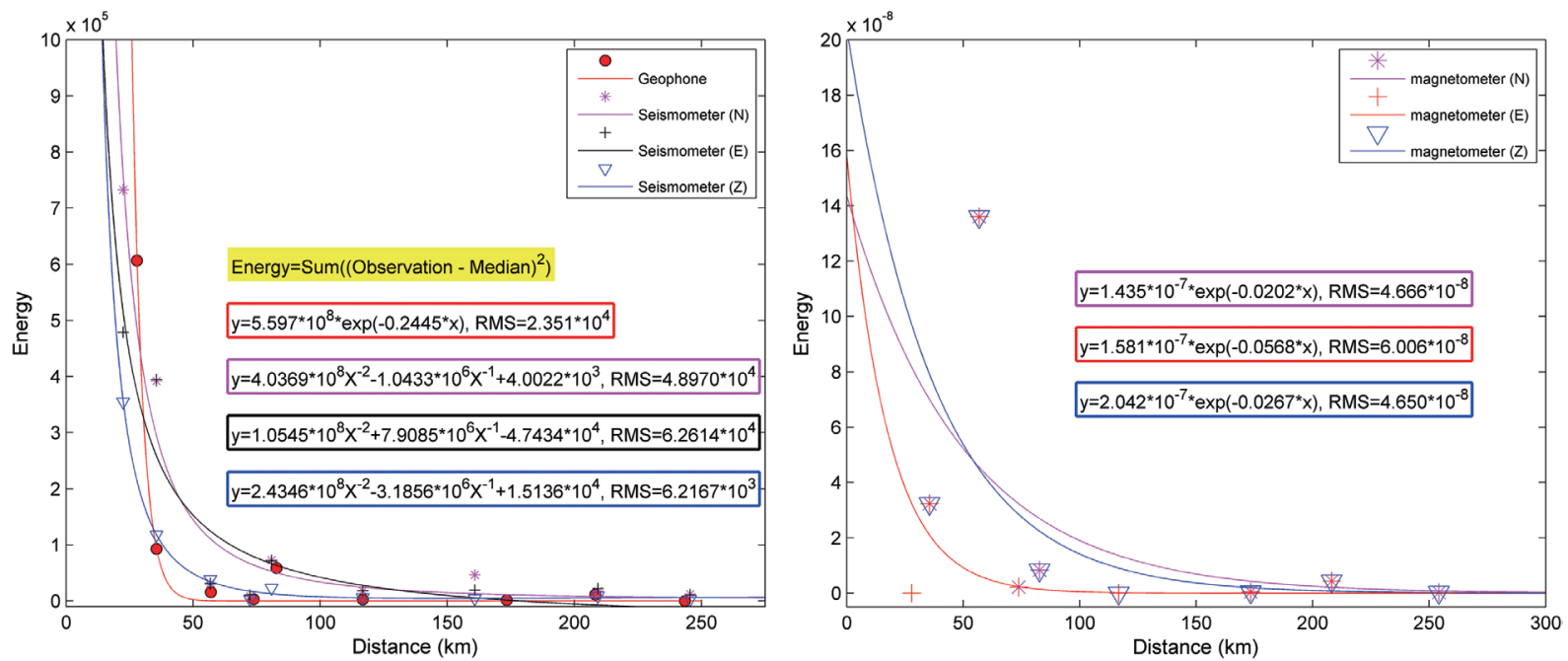

Fig. 4. The packet energy versus the distance of a station to the epicenter for the geophone, seismometer, and magnetometer. (Color online only)

a seismometer recording the acceleration and a geophone (magnetometer) response to the velocity (shaking/tilting) of the ground motion.

To compute the propagation speed or velocity, the arrival time of the ticking, the moment of the quantity beginning to fluctuate, and that of the packet maximum of the quantities at each station are identified. It is found at each station that the time differences among the QuakeFinder quantities of the ticking time and the packet time are generally within $1 \mathrm{sec}$. Therefore, for the QuakeFinder quantities, we can simply apply the ticking time and the packet time of the geophone fluctuations obtained at each station to compute the ticketing and the packet velocities, accordingly. To find the arrival time of the packet maximum, the packet of each quantity at the nearest station (Station A) is used as a reference, and a cross correlation of the packet between the nearest one and 
the rests is computed. When the greatest correlation value is reached, the maximum packet time is obtained. In fact, we also apply a band pass filter of $0.5-2.5 \mathrm{~Hz}$ on the raw data to double check and confirm if the obtained ticking and packet times have been correctly identified (also see, Table 2). Note that the co-seismic signatures in Station J can be clearly identified after the filtering process (Fig. 5). The linear fitness of the two times versus their distances shows that the velocities of the ticking and the packet are about 6.6 and $3.4 \mathrm{~km} \mathrm{~s}^{-1}$, corresponding to the compressional P-waves and the Rayleigh waves, respectively (Fig. 6). Note that at Station D, the ticking and the packet take much longer time than the fitted ones, respectively. Meanwhile, at Station F, the packet of the infrasound system is about $5-15 \mathrm{sec}$ later than that in the seismic waves. Although, the other infrasound system is somewhat far from Station C, B, and F, the packet time the infrasound system lags that of the fitted.

\section{DISCUSSION}

Gershenzon et al. (1993) found the earthquake magnitude dependence of co-seismic geomagnetic variations for piezomagnetic, electro-kinetic, and induction (dynamo) effects. Many scientists (Honkura et al. 2002; Abdul Azeez et al. 2009; Widarto et al. 2009; Gao et al. 2014) conducted observations and simulations, and proposed mechanism to explain co-seismic magnetic pulsations. We compare our results with these studies, and find our low-frequency magnetic (a) WT / KAU049

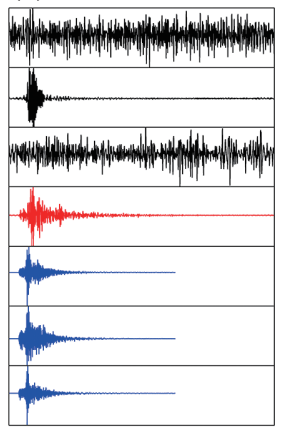

(b) KS / KAU050

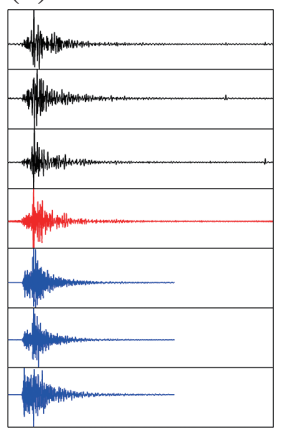

(c) TT / TTN029/ LD

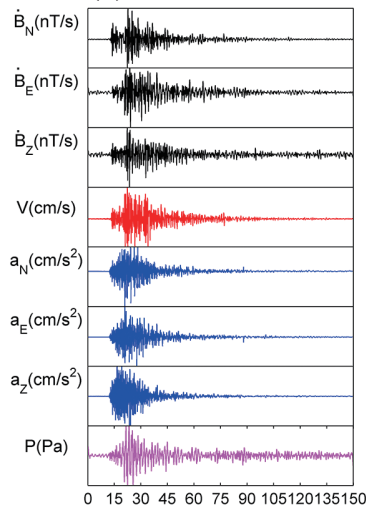

(d) $\mathrm{CC} / \mathrm{CHY} 036$

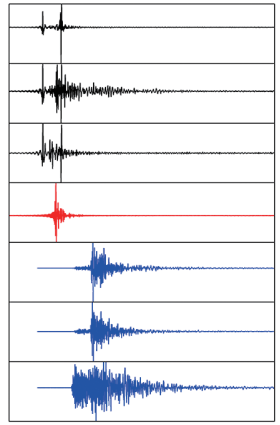

(e) SW / TTN016

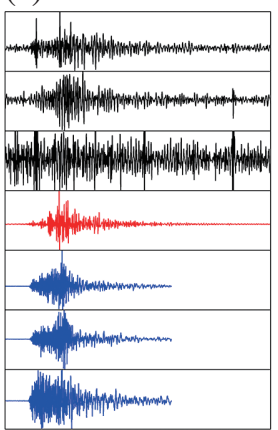

(f) FL / HWA042/ TP

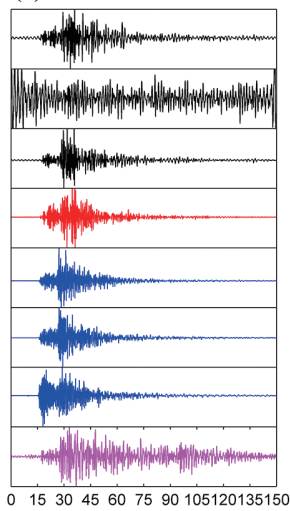

(g) KD / KAU043

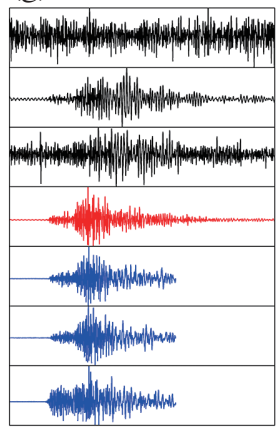

(h) $\mathrm{TH} / \mathrm{TCU} 088$

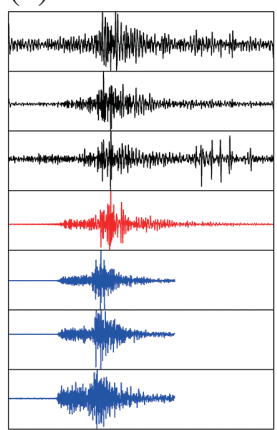

(i) $\mathrm{HH} / \mathrm{TCU} 023$

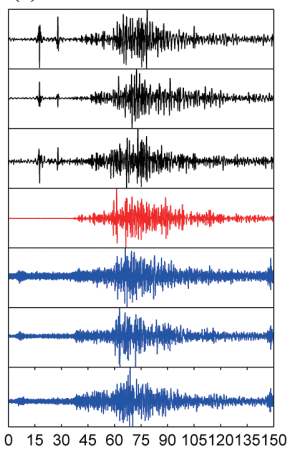

(j) FG / ILA035

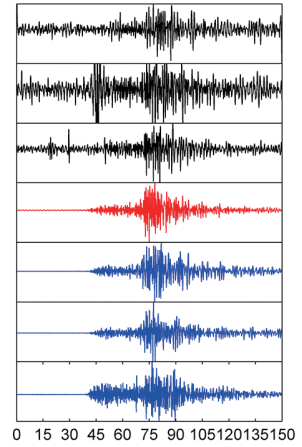

$0 \longdiv { 1 5 3 0 4 5 6 0 7 5 9 0 1 0 5 1 2 0 1 3 5 1 5 0 }$

\section{Time after earthquake (sec)}

Fig. 5. Filtered data of Fig. 2. (Color online only) 


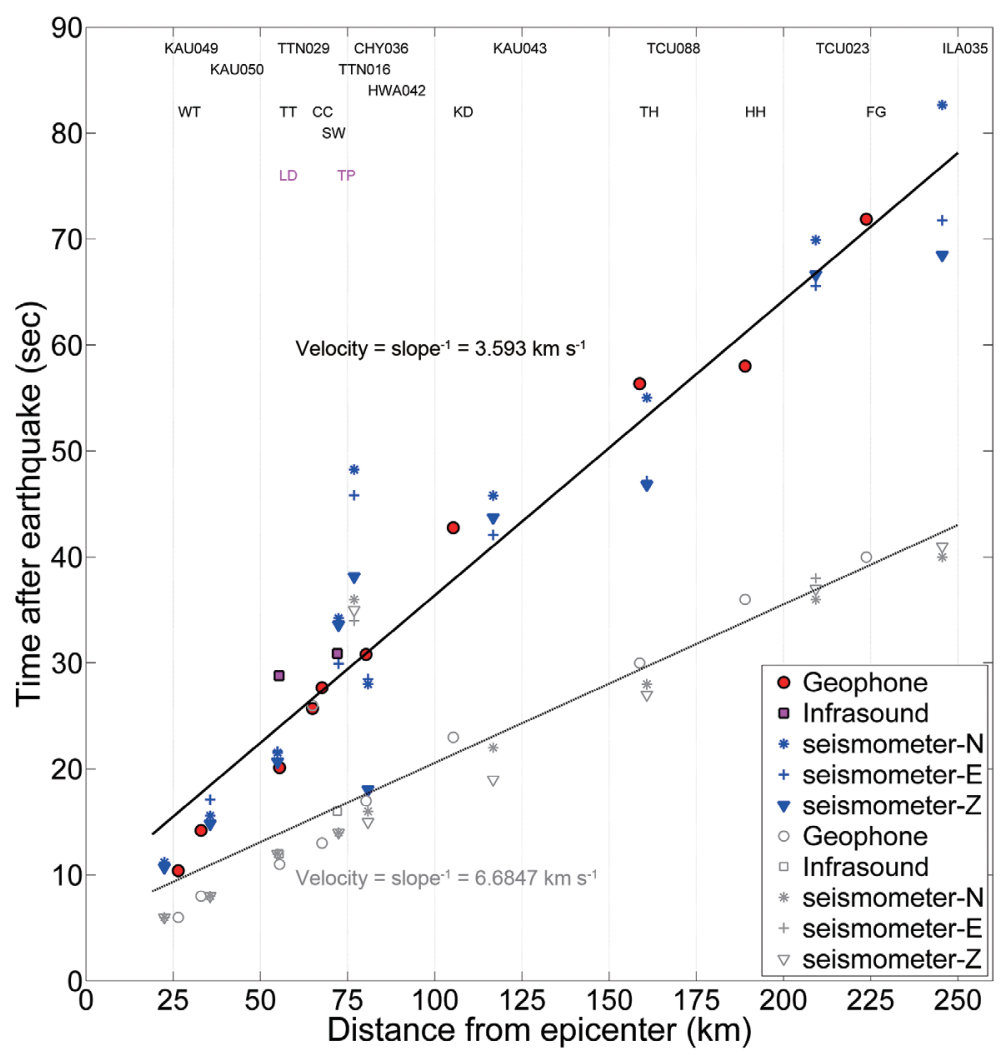

Fig. 6. The ticking time (solid symbols) and the maximum packet time (open symbols) versus distance to the epicenter. (Color online only)

pulsations most likely result from motions of ground water due to seismic waves (i.e., electro-kinetic effect) observed by Abdul Azeez et al. (2009) and simulated by Ren et al. (2012, 2015, 2016), while the high-frequency ones are due to shaking/tilting effects (i.e., magnetometer coil motion) reported by Widarto et al. (2009) and Gao et al. (2014). It has been found that the co-seismic signatures of the geophone and magnetometer at CC (i.e., Chung Cheng University) are very different from those at the rest stations. This suggests the underground structure at $\mathrm{CC}$ being complex. We further examine co-seismic signatures of the magnetometers and the geophones at CC and KS (arbitrary choosing as a reference). Figure 7 reveals that the geophones simply recording the seismic waves last about $75 \mathrm{sec}$ at two stations, while the magnetic pulsations continue upto $1200 \mathrm{sec}$, especially the $\mathrm{z}$ component with much larger pulsation amplitude, at CC. We examining and comparing the magnetometer data at the 10 stations find that at each station, the $\mathrm{z}$ component generally yields the greatest co-seismic pulsation, and the duration of co-seismic magnetic pulsations is slightly longer than that of the co-seismic geophone fluctuations, except that those at CC last upto $1200 \mathrm{sec}$. This long lasting magnetic pulsation may result from a sufficiently strong medium heterogeneity, fluid-pressure gradient [most likely ground water (Abdul Azeez et al. 2009)], and/or a finite faulting in porous media proposed by Ren et al. $(2012,2016)$. Nevertheless, the long lasting co-seismic pulsations appearing at the $\mathrm{CC}$ station might be due to the ground water and underground structure around Meishan fault being complex (Yen et al.2008; Ching et al. 2011; Wilcox et al. 2011).

By contrast, researchers (Iyemori et al. 2005; Hao et al. 2013; Yen et al. 2015; Liu et al. 2016a) observe that seismo-magnetic pulsations with much longer period (low frequency) constantly lag seismic wave pulses by about $200+$ minutes, suggesting that ionospheric conductivity affects magnetic fields. Since there is almost no time lag between magnetic pulsations and seismic waves at each co-located station, the co-seismo magnetic pulsation is unlikely related to the ionospheric conductivity.

The geophone is setup in the northward direction. Therefore, the pattern of geophone fluctuations is similar to that of seismic waves, especially in the horizontal directions, at each station. The similarities in the power spectra of the co-seismic geophone fluctuations and seismograms' indicate a geophone can be used to study seismic waves. The packet energy in the geophone (also magnetometer) yields an exponential decay to the distance to the epicenter, while the energy in the seismic is inversely proportional to the square of the distance. This suggests that the mechanisms for detecting seismic waves of the QuakeFinder system and seismometers are different. The greatest differences in the computed and the fitted ticking/packet arrival times and the 

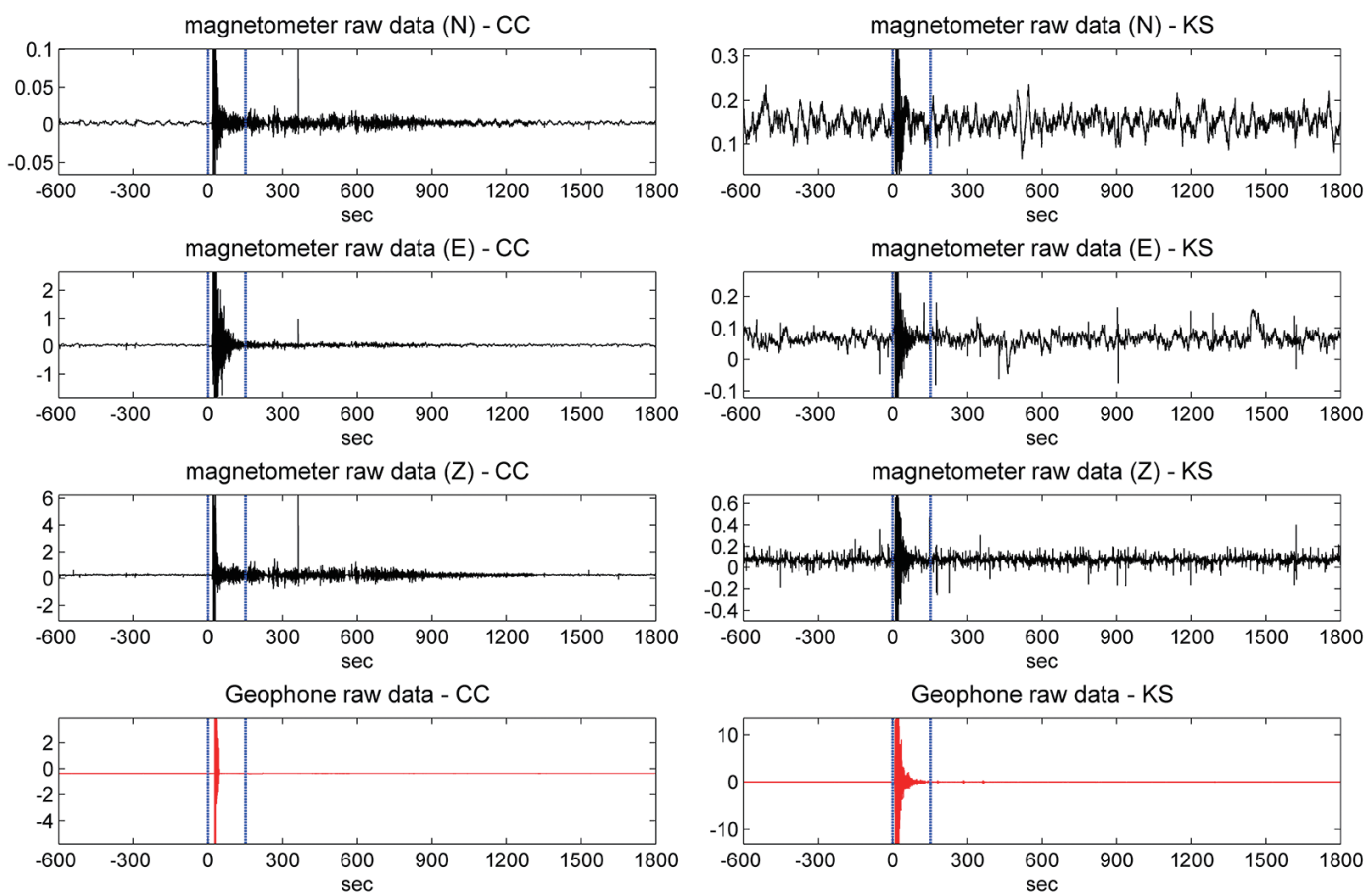

Fig. 7. Extended and magnified plots of magnetometers and geophones at CC (left) and KS (right). Two vertical lines in each panel stand for the data length plotted in Fig. 2. (Color online only)

most different wave packets of all the quantities appear at Station D [Chung Cheng University $\left.\left(23.57^{\circ} \mathrm{N}, 120.48^{\circ} \mathrm{E}\right)\right]$, which suggests the underground structure and electromagnetic properties over the region being rather complex.

The infrasound system has the sensitivity of $0.01 \mathrm{~Pa}$ with the frequency range $0.005-2.0 \mathrm{~Hz}$ (period of $0.5-$ $200 \mathrm{sec}$ ). Figure 3 shows that the system is suitable to detect long-period oscillations. The sample rate of the system $1.0 \mathrm{~Hz}$ has been changed to $10 \mathrm{~Hz}$, when it was setup in Taiwan. Figure 5 reveals that clear filtered co-seismo infrasound oscillations. It can be seen that the co-seismo infrasound oscillations lag the co-located seismic waves by about $5-15$ sec (see Stations C and F, also Fig. 6). Liu et al. (2016a) study the vertical propagation of disturbances triggered by seismic waves of the 11 March 2011 M 9.0 Tohoku earthquake over Taiwan. However, they find that there is no time lag between co-seismic infrasound fluctuations and the colocated seismic waves. They further observe that the STADs of co-seismic infrasound fluctuations can further vertically travel into the ionosphere and interact with the ionized gas, which result in changes of the magnetic field, the Doppler shift, and the total electron content (TEC) in about 400+, $500+$, and $800+$ sec delay, respectively during the Tohoku Earthquake. The discrepancy of with and without time delay between seismic waves and co-seismic infrasound oscillations might result from the former being near and the latter being far away from the epicenter. For a long distance (for example, Tohoku to Taiwan), seismic waves can disperse and simultaneously disturb a large area of the Earth's sur- face, which acts a plane source vertically pumping the atmosphere and launching STADs into the upper atmosphere and then the ionosphere. In contrast, for a short distance of the stations to the Meinong epicenter, the seismic wave packet quickly decays as a point source (Fig. 4). Thus, vertical motions of Earth's surface over the station area (Fig. 1) are not simultaneous and/or coherent, which cannot efficiently disturb and/or pump the near Earth's surface atmosphere. In fact, we find no obvious changes of the magnetic field, the Doppler shift, and the TEC in 400+, 500+, and 800+ sec after the Meinong Earthquake. On the other hand, Liu et al. (2010) observe STIDs of the GPS TEC triggered by the 21 September 1999 M 7.6 Chi-Chi Earthquake. It might be that the STADs of the Meinong Earthquake are much smaller than those of the Chi-Chi Earthquake to induce STADs.

\section{SUMMARY AND CONCLUSION}

In this study, we show that induction magnetometers, geophones, and even infrasound systems with high sampling rate can easily detect co-seismic signatures. During the Meinong Earthquake, the co-seismic magnetic pulsations most likely result from electro-kinetic effects due to motions of ground water disturbed by seismic waves and shaking/tilting effects caused by magnetometer coil motions. The 150 300 (even $1200 \mathrm{sec}$ ) long lasting co-seismic pulsations also suggest the ground water being essential. The co-seismic infrasound oscillations lagging co-located seismic waves by about 5 - $15 \mathrm{sec}$ that might be due to the study large area not 
disturbing the near Earth's surface atmosphere simultaneously and coherently during the Meinong Earthquake.

Acknowledgements This study is partially supported by the grant of Ministry of Science and Technology (MOST) to National Central University, MOST 105-2119-M-008-020 and by the project 41474138 of National Natural Science Foundation of China. The authors gratefully acknowledge Center Weather Bureau in Taiwan for publishing seismometer data (http://gdms.cwb.gov.tw/index.php), QuakeFinder for providing magnetometer and geophone data (https:// www.quakefinder.com/), and Common Data Service Platform of Atmospheric Science Data in Taiwan - Taiwan Space Science Database for publishing infrasound data (http://sdbweb.ss.ncu.edu.tw/ipei download.html). The authors wish to thank reviewers providing useful suggestions and comments, which have this paper a better presentation.

\section{REFERENCE}

Abdul Azeez, K. K, C. Manoj, K. Veeraswamy, and T. Harinarayana, 2009: Co-seismic EM signals in magnetotelluric measurement-a case study during Bhuj earthquake (26 $6^{\text {th }}$ January 2001), India. Earth Planets Space, 61, 973-981, doi: 10.1186/BF03352947. [Link]

Ching, K. E., R. J. Rau, K. M. Johnson, J. C. Lee, and J. C. Hu, 2011: Present-day kinematics of active mountain building in Taiwan from GPS observations during 1995-2005. J. Geophys. Res., 116, B09405, doi: 10.1029/2010JB008058. [Link]

Davies, K., 1990: Ionospheric Radio, IEE electromagnetic wave series, Vol. 31, Peter Peregrinus Ltd., London, $580 \mathrm{pp}$.

Gao, Y., X. Chen, H. Hu, J. Wen, J. Tang, and G. Fang, 2014: Induced electromagnetic field by seismic waves in Earth's magnetic field. J. Geophys. Res., 119, 56515685, doi: 10.1002/2014JB010962. [Link]

Gershenzon, N. I., M. B. Gokhberg, and S. L. Yunga, 1993: On the electromagnetic field of an earthquake focus. Phys. Earth Planet. Inter., 77, 13-19, doi: 10.1016/0031-9201(93)90030-D. [Link]

Hao, Y. Q., Z. Xiao, and D. H. Zhang, 2013: Teleseismic magnetic effects (TMDs) of 2011 Tohoku earthquake. J. Geophys. Res., 118, 3914-3923, doi: 10.1002/ jgra.50326. [Link]

Honkura, Y., M. Matsushima, N. Oshiman, M. K. Tuncer, S. Baris, A. Iio, and A. M. Isikara, 2002: Small electric and magnetic signals observed before the arrival of seismic wave. Earth Planets Space, 54, e9-e12, doi: 10.1186/BF03352449. [Link]

Iyemori, T., T. Kamei, Y. Tanaka, M. Takeda, T. Hashimoto, T. Araki, T. Okamoto, K. Watanabe, N. Sumitomo, and N. Oshiman, 1996: Co-Seismic geomagnetic variations observed at the 1995 Hyogoken-Nanbu Earth- quake. J. Geomag. Geoelectr., 48, 1059-1070, doi: 10.5636/jgg.48.1059. [Link]

Iyemori, T., M. Nose, D. Han, Y. Gao, M. Hashizume, N. Choosakul, H. Shinagawa, Y. Tanaka, M. Utsugi, A. Saito, H. McCreadie, Y. Odagi, and F. Yang, 2005: Geomagnetic pulsations caused by the Sumatra earthquake on December 26, 2004. Geophys. Res. Lett., 32, L20807, doi: 10.1029/2005GL024083. [Link]

Liu, J. Y., Y. N. Huang, and F. T. Berkey, 1993: The phase relationship between ULF geomagnetic pulsations and HF Doppler frequency shift oscillations on March 24, 1991. J. Geomag. Geoelectr., 45, 109-114, doi: 10.5636/jgg.45.109. [Link]

Liu, J. Y., Y. B. Tsai, S. W. Chen, C. P. Lee, Y. C. Chen, H. Y. Yen, W. Y. Chang, and C. Liu, 2006: Giant Ionospheric Disturbances Excited by the M9.3 Sumatra Earthquake of 26 December 2004. Geophys. Res. Lett., 33, L02103, doi: 10.1029/2005GL023963. [Link]

Liu, J. Y., H. F. Tsai, C. H. Lin, M. Kamogawa, Y. I. Chen, C. H. Lin, B. S. Huang, S. B. Yu, and Y. H. Yeh, 2010: Coseismic ionospheric disturbances triggered by the Chi-Chi earthquake. J. Geophys. Res., 115, A08303, doi: 10.1029/2009JA014943. [Link]

Liu, J. Y., C. H. Chen, Y. Y. Sun, C. H. Chen, H. F. Tsai, H. Y. Yen, J. Chum, J. Lastovicka, Q. S. Yang, W. S. Chen, and S. Wen, 2016a: The vertical propagation of disturbances triggered by seismic waves of the 11 March 2011 M9.0 Tohoku Earthquake over Taiwan. Geophys. Res. Lett., 43, 1-7, doi: 10.1002/2015GL067487. [Link]

Liu, J. Y., Y. B. Tsai, C. H. Chen, Y. I. Chen, and H. Y. Yen, 2016b: Integrated, Search for Taiwan Earthquake Precursors (iSTEP). IEEJ Trans. Fund. Materials, 136, 214-220, doi: 10.1541/ieejfms.136.214. [Link]

Liu, J. Y., L. C. W. Chang, C. K. Chao, M. Q. Chen, Y. H. Chu, L. N. Hau, C. M. Huang, C. L. Kuo, L. C. Lee, L. H. Lyu, C. H. Lin, C. J. Pan, J. H. Shue, C. L. Su, L. C. Tsai, Y. H. Yang, C. H. Lin, R. R. Hsu, and H. T. Su, 2016c: The fast development of solar terrestrial sciences in Taiwan. Geosci. Lett., 3, 1-12, doi: 10.1186/ s40562-016-0049-0. [Link]

Mutschlecner, J. P. and R. W. Whitaker, 2005: Infrasound from earthquakes. J. Geophys. Res., 110, D01108, doi: 10.1029/2004JD005067. [Link]

Ren, H., X. Chen, and Q. Huang, 2012: Numerical simulation of coseismic electromagnetic fields associated with seismic waves due to finite faulting in porous media. Geophys. J. Int., 188, 925-944, doi: 10.1111/j.1365246X.2011.05309.x. [Link]

Ren, H., J. Wen, Q. Huang, and X. Chen, 2015: Electrokinetic effect combined with surface-charge assumption: a possible generation mechanism of coseismic EM signals. Geophys. J. Int., 200, 835-848, doi: 10.1093/gji/ 
ggu435. [Link]

Ren, H., Q. Huang, and X. Chen, 2016: Numerical simulation of seismo-electromagnetic fields associated with a fault in a porous medium. Geophys. J. Int., 206, 205220, doi: 10.1093/gji/ggw144. [Link]

Shearer, P. M., 1999: Introduction to Seismology, Cambridge University Press, $260 \mathrm{pp}$.

Widarto, D. S., T. Mogi, Y. Tanaka, T. Nagao, K. Hattori, and S. Uyeda, 2009: Co-seismic geoelectrical potential changes associated with the June 4, 2000's earthquake (Mw7.9) in Bengkulu, Indonesia. Phys. Chem. Earth, 34, 373-379, doi: 10.1016/j.pce.2008.09.009. [Link]

Wilcox, T., K. Mueller, P. Upton, Y. G. Chen, S. T. Huang, B. J. Yanites, and G. Tucker, 2011: Linking Taiwan's subcritical Hsuehshan Range topography and foreland basin architecture. Tectonics, 30, TC4011, doi:
10.1029/2010TC002825. [L Link]

Xia, Y. Q., J. Y. Liu, X. Y. Cui, J. Z. Li, W. S. Chen, and C. Y. Liu, 2011: Abnormal Infrasound Signals before $92 \mathrm{M} \geq 7.0$ Worldwide Earthquakes during 2002-2008. J. Asian Earth Sci., 41, 434-441, doi: 10.1016/j.jseaes.2010.04.015. [Link]

Yen, H. Y., C. R. Chen, Y. T. Lo, T. C. Shin, and Q. Li, 2015: Seismo-geomagnetic pulsations triggered by Rayleigh waves of the 11 March 2011 M 9.0 Tohokuoki earthquake. Terr. Atmos. Ocean. Sci., 26, 95-101, doi: 10.3319/TAO.2014.10.09.01(T). [Link]

Yen, J. Y., K. S. Chen, C. P. Chang, and W. M. Boerner, 2008: Evaluation of earthquake potential and surface deformation by Differential Interferometry. Remote Sens. Environ., 112, 782-795, doi: 10.1016/j. rse.2007.06.012. [Link] 